\title{
AÇÕES DE EXTENSÃO PARA INTEGRAR MULHERES EM VULNERABILIDADE SOCIAL NA ÁREA DE TECNOLOGIAS DA INFORMAÇÃO E COMUNICAÇÃO
}

\author{
Renata Luiza da Costa ${ }^{1}$ \\ ORCID: 0000-0002-2638-6314 \\ Alcides Hermes Thereza Júnior ${ }^{2}$ \\ ORCID: 0000-0001-6628-2686 \\ DÉbora G. DE S. GUINATI ${ }^{3}$ \\ ORCID: 0000-0002-6847-6836 \\ Stéfany de Castro Sousa ${ }^{4}$ \\ ORCID: 0000-5791-5952
}

1 Professora do curso de Sistemas de Informação e curso Técnico em Informática do Instituto Federal de Educação, Ciência e Tecnologia de Goiás (IFG). Doutora em Educação pela PUC_GO com doutorado sanduíche na Universidade de Sherbrooke no Canadá. Av. Universitária s/n 75400-ooo, Vale das Goiabeiras, Inhumas, Goiás, Brasil. Contato: (62)3514-9501. E-mail: (renata.costa@ifg.edu.br).

2 Professor do curso de Letras da Universidade Estadual de Goiás (UEG). Mestre em Linguística Aplicada (UFU). Av. Araguaia, 400 - Vila Lucimar, Inhumas - GO, 75400-ooo. Contato: (62) 3514-3122. E-mail: (alcides.junior@ueg.br).

3 Estudante do curso de Sistemas de Informação do Instituto Federal de Educação, Ciência e Tecnologia de Goiás (IFG). Bolsista de extensão. Av. Universitária s/n 75400-ooo, Vale das Goiabeiras, Inhumas, Goiás, Brasil. Contato: (62)3514-9501. E-mail: (guinati7@gmail.com).

4 Estudante do curso de Sistemas de Informação do Instituto Federal de Educação, Ciência e Tecnologia de Goiás (IFG). Bolsista de extensão. Av. Universitária s/n 75400-000, Vale das Goiabeiras, Inhumas, Goiás, Brasil. Contato: (62)3514-9501 E-mail: (stefanydecastrosousa@hotmail.com). 
Resumo: O presente artigo traz reflexões a respeito da vulnerabilidade social e da desigualdade de gênero no Brasil, em âmbito geral e em profissões da área das Ciências Exatas, a partir de dados do Atlas da Violência no Brasil, de pesquisas a respeito da mão de obra para área de Tecnologia da Informação e Comunicação, e de levantamento bibliográfico sobre pesquisas de gênero em relação às profissões das Exatas. A partir desses dados, são descritos os objetivos do Instituto Federal de Goiás (IFG) quanto às ações de Extensão e apresentada uma proposta voltada para mulheres em situação vulnerável ligada à área profissional da Informática. Também são descritos resultados parciais do curso Mulheres na Informática. Apesar de ter aberto 50 vagas, apenas 28 foram preenchidas. O curso está no seu quarto mês de execução e conta com 20 estudantes. O acompanhamento inicial mostra que embora haja muitas mulheres com necessidades de reinserção no mercado, ainda é preciso desenvolver estratégias para seu interesse e manutenção num curso na área de Informática.

Palavras-chave: Vulnerabilidade social. Desigualdade de gênero. Tecnologias da Informação e Comunicação (TIC). Extensão Universitária.

\title{
EXTENSION ACTIONS TO INTEGRATE WOMEN IN SOCIAL VULNERABILITY IN THE AREA OF INFORMATION AND COMMUNICATION TECHNOLOGIES
}

\begin{abstract}
This article reflects on social vulnerability and gender inequality in Brazil, in general and in Exact Sciences professions, based on data from the Atlas of Violence in Brazil, research on the workforce in the area of Information and Communication Technology, and bibliographic survey on gender research in relation to the Exact area professions. From these data, the aims of Goiás Federal Institute (IFG) regarding the extension actions are described and a proposal for women in vulnerable situation and the professional area of Computing is presented. Partial results from the Women in Informatics course are also described. Despite having opened 50 vacancies, only 28 were filled. The course is in its fourth month of execution and has 20 students. The initial follow-up shows that although there are many women that need reintegration in the labor market, it is still necessary to develop strategies for their interest and maintenance in a computer course.
\end{abstract}

Keywords: Social vulnerability. Gender inequalities. Information and Comunication Technology Profession. Extension Courses.

\section{ACCIONES DE EXTENSIÓN PARA INTEGRAR A LAS MUJERES EN VULNERABILIDAD SOCIAL EN EL ÁMBITO DE LAS TECNOLOGÍAS DE LA INFORMACIÓN Y LA COMUNICACIÓN}

Resumen: Este artículo reflexiona sobre la vulnerabilidad social y la desigualdad de género en Brasil, en general y en las profesiones de Ciencias Exactas, con base en datos del Atlas de la Violencia en Brasil. investigación sobre la fuerza laboral en el área de Tecnología de Información y Comunicación, y encuesta bibliográfica sobre investigación de género en relación con las 
profesiones Exatas. A partir de estos datos, se describen los objetivos del IFG con respecto a las acciones de extensión y se presenta una propuesta dirigida a mujeres vulnerables y al área profesional de Informática. También se describen resultados parciales del curso Mujeres en informática. A pesar de haber abierto 50 vacantes, solo se completaron 28. El curso está en su cuarto mes de ejecución y tiene 20 estudiantes. El seguimiento inicial muestra que, aunque hay muchas mujeres que necesitan reintegrarse en el mercado, aún es necesario desarrollar estrategias para su interés y mantenimiento en un curso de informática.

Palabras claves: Vulnerabilidad social. Desigualdad de género. Tecnologías de la información y la comunicación (TIC). Extensión Universitaria.

\section{VULNERABILIDADE SOCIAL E DESIGUALDADES}

O Brasil, apesar do intenso período de desenvolvimento econômico entre 2004 e 2012, em que políticas educacionais e assistenciais foram ampliadas melhorando as possibilidades das classes baixas terem acesso a serviços de formação, a partir de 2014 o país entrou em processo de estagnação e recessão que, em termos de vulnerabilidade social, têm conduzido ao regresso de índices preocupantes.

Os índices de vulnerabilidade social (IVS), no Brasil, embora tenham apresentado significativas melhoras entre os anos de 2000 a 2010, após 2012, começaram a apresentar estagnação e, em 2014, apresentaram nova alta (ROCHA et al, 2015; 2017). Este cenário indica que é preciso manter e ampliar políticas e programas sociais ligados a esse tema, visando à melhoria social de grupos que vivem em extrema pobreza no Brasil:

Mesmo com significativos avanços, ao desagregarmos estas informações, podemos observar as desigualdades latentes entre negros e brancos, mulheres e homens, ou indivíduos que residem em áreas rurais ou urbanas, denotando as diferentes faces das desigualdades para distintos extratos da nossa sociedade. (ROCHA et al, 2017, p. 19).

As diferenças de cor, sexo e ocupação geográfica levam a índices piores, em alguns casos. Sabe-se, por exemplo, que as taxas de mulheres, mães de família e adolescentes entre 10 e 17 anos grávidas, ainda é alta (7\%) no Brasil (ROCHA et al, 2017). Além disso, destaca-se os $8 \%$ de analfabetismo de pessoas acima de 15 anos e os $9 \%$ de pessoas entre 15 e 24 anos que não estudam e nem trabalham, e possuem renda domiciliar per capita igual ou inferior a meio salário mínimo.

No caso das mulheres brasileiras, de 2000 a 2010, o IVS para mulheres diminuiu 28\%, passando a vulnerabilidade de alta para média (ROCHA et al, 2017). A partir de 2010, esses índices melhoraram no Centro-Sul do Brasil e passaram a enquadrar o País na categoria de baixa vulnerabilidade. Entretanto, quando é 
analisada, especificamente, a dimensão Renda e Trabalho, observa-se que há gradativo aumento da presença feminina no mundo do trabalho, porém sem a garantia da equitativa igualdade de gênero nos ambientes profissionais. Esses dados revelam "a persistente desigualdade entre homens e mulheres no mercado de trabalho e, consequentemente, em níveis ainda expressivos de vulnerabilidade das mulheres no Brasil." (ROCHA et al, 2017, p. 89).

Ademais, dados do Atlas da Violência no Brasil (IPEA, 2018) mostram que em dez anos (2006-2016) a taxa de feminicídio aumentou 6,4\% e o Estado de Goiás está entre as três unidades federativas com índices mais altos no país. A relação da vulnerabilidade social com atos violentos fatais pode ser percebida no fato de que

uma vítima fatal muitas vezes já foi vítima de uma série de outras violências de gênero, por exemplo: violência psicológica, patrimonial, física ou sexual. Ou seja, muitas mortes poderiam ser evitadas, impedindo o desfecho fatal, caso as mulheres tivessem tido opções concretas e apoio para conseguir sair de um ciclo de violência. (IPEA, 2018, p. 46).

Para o enfrentamento das situações de violência e vulnerabilidade social feminina, é preciso, para além da ampliação dos programas de assistência social e apoio à mulher, a proposição de "alternativas de vida para as mulheres" (IPEA, 2018, p. 48), o que inclui, indiscutivelmente, formação e profissionalização. Por esse motivo, destaca-se o objetivo 4 da agenda de prevenção à violência no Brasil: "Assegurar a educação inclusiva e equitativa de qualidade, e promover oportunidades de aprendizagem ao longo da vida para todos" (IPEA, 2018, p. 84). Para a realização desse objetivo, é preciso oferecer cursos de formação que possam colaborar com a formação de mulheres e seu reinício em uma alternativa profissional e de vida.

Considerando a necessidade de formação que pudesse dar possibilidade condição de empregabilidade para mulheres em situação vulnerável, foi feito um levantamento a respeito das áreas profissionais que têm menor participação de mulheres e, ao mesmo tempo, apresentam demanda crescente por profissionais. Nesse levantamento, aparece muita desigualdade de gênero nas profissões ligadas às Tecnologias da Informação e Comunicação (TIC). Assim, é discutido na próxima seção o tema da desigualdade de gênero nas profissões, em geral, e na área de TIC.

\section{A DESIGUALDADE DE GÊNERO NAS PROFISSÕES}

A respeito da importância das Tecnologias Digitais da Informação e Comunicação (TDIC) para os segmentos profissionais de hoje e no futuro, pode-se citar a BNCC (Base Nacional Curricular Comum) que, reconhecendo sua relevância, 
indica conhecimentos de TDIC como competências imprescindíveis desde a Educação Básica:

Compreender, utilizar e criar tecnologias digitais de informação e comunicação de forma crítica, significativa, reflexiva e ética nas diversas práticas sociais (incluindo as escolares) para se comunicar, acessar e disseminar informações, produzir conhecimentos, resolver problemas e exercer protagonismo e autoria na vida pessoal e coletiva. (BRASIL, 2017, p. 9).

A importância das TDIC é algo crescente no cenário mundial, pois seus avanços científico-tecnológicos têm levado à transformações no modo de vida das pessoas, nas relações sociais e de trabalho. Cada vez mais atividades e profissões diversas demandam conhecimento de tecnologia digital para se cumprir algo. $\mathrm{Na}$ sociedade brasileira, as TDIC, após a década de 1990, tiveram sua importância acentuada em termos profissionais, de exercício da cidadania e até lazer, pois o governo brasileiro colocou em prática diversos incentivos com esses fins, especificamente. Por outro lado, para tanta produção digital é preciso mais profissionais da área. Atualmente, já existe um grande déficit de profissionais nessa aŕea pelo mundo e a previsão é que isso piore devido aos baixos números de formandos nas áreas de TIC, enquanto a economia da informação só cresce (SOFTEX, 2013a; 2013b; LAUDON; LAUDON, 2006). Por isso, há ações espalhadas pelo mundo incentivando a participação das mulheres nas áreas de TIC e engenharias. Sabe-se que somente com a procura masculina por esses cursos não será possível atender a demanda profissional que está em intenso avanço devido ao acelerado desenvolvimento tecnológico da área digital.

Quando se analisa os problemas de desigualdade de gênero, da vulnerabilidade social feminina e da demanda por profissionais no uso de TDIC, a situação é muito ruim, pois, historicamente, as mulheres são estigmatizadas como quem tem inteligência menor para atuação profissional em tal área. Sabe-se que o número de mulheres no mercado de trabalho tem aumentado (IBGE, 2017), porém a atuação delas nas Exatas ainda é pequena. Tal situação pode ser vista dentro do próprio IFG câmpus Inhumas: Nos oito períodos do curso de bacharelado em Sistemas de Informação, por exemplo, com aproximadamente 80 alunos, há apenas 3 meninas. Algumas pesquisas (CHASSOT, 2011a; BARRETO, 2014; BOLZANI, 2017; CUNHA et al, 2014) mostram que, dentre diversas razões para tal situação, as mais fortes são de cunho sociohistórico e cultural, o que torna viável o desenvolvimento de estratégias que possam colaborar com a mudança de um pensamento preconceituoso em relação às mulheres atuarem nessas áreas. 
Quanto à profissão cientista, as pesquisadoras representam quase a metade dos registros do $\mathrm{CNPq}$, entretanto, quando a avaliação é por áreas, as Ciências Humanas e Biológicas concentram em torno de $74 \%$ delas, restando em torno de $26 \%$ nas Ciências Exatas (CHASSOT, 2011a; BARRETO, 2014; BOLZANI, 2017; CUNHA et al, 2014). Esse fenômeno se repete na América do Norte e Europa, mas, ao longo dos anos, naqueles continentes, a quantidade de mulheres ultrapassou a de homens em algumas áreas, enquanto que, nas Exatas, permaneceram bem abaixo.

As causas dessa desigualdade relacionada ao gênero em termos de atuação profissional podem estar associadas a diversas razões, mas destaca-se o fato de que não há muito tempo as mulheres são estimuladas a estudar e trabalhar e, ainda menos, que isso seja em áreas que lidam com instrumentos ou cálculos, por exemplo. Há fatores culturais que separam, há muito tempo, atividades, exercícios e brinquedos de menina e de meninos, criando estereótipos e preconceitos. Cunha et al (p. 408) explicam que

enquanto os meninos recebem mais estímulos para lidar com instrumentos associados ao mundo masculino, como ferramentas, carros, máquinas, computadores e outros, as meninas passam por um processo de socialização diferenciado e são estimuladas a lidarem com assuntos que envolvem mais as áreas de saúde, educação e bem-estar, que acabam fazendo parte dos seus interesses futuros.

Para Chassot (2011b), trata-se do processo histórico-cultural da humanidade com interesses limitantes para as mulheres, não lhes oferecendo liberdade de expressão e atuação, sendo a raiz desses limites a religião. Outra razão que não pode ser descartada, segundo este mesmo autor, é a biológica: a maternidade que, por envolver tarefas especificamente femininas como a gestação e a lactação, por exemplo, pode distanciar a mulher do trabalho por um período longo dificultando sua volta e reinserção. Diante de razões históricas, culturais e biológicas, o fato é que estigmas de incapacidade da mulher para lidar com matemática, questões espaciais e assuntos das ciências exatas em geral, foram consolidados ao longo da história da humanidade, fazendo com que até os dias de hoje, mulheres acreditem nessa insuficiência, o que influencia suas escolhas durante a vida.

Aires et al (2018), em pesquisa com meninas do Ensino Médio, revelaram como barreiras para se escolher cursos da área das Ciências Exatas, principalmente, o machismo e a crença de que as mulheres são incapazes de lidar com tecnologia. Ademais, Macedo et al (2018) mostraram que as mulheres apresentam muito mais argumentos contra a área de exatas do que pessoas do sexto masculino e a escolha do curso superior por elas é influenciada pelas opiniões de amigos e familiares, ou seja, se preocupam com a opinião da sociedade. 
Pesquisas da IAB (2015) e ISACA (2016), específicas no setor de TI, mostraram que a mão de obra feminina também não passa de $25 \%$ do total. Os dados da ISACA (2016) destacam, ainda, a dificuldade das empresas em contratar profissionais qualificados para tal área.

Outras pesquisas na área da TI (MACEDO et al, 2018; MAQUINÉ, 2017; SANTOS; CANEVER; FROTTA, 2011) corroboram a força das influências históricas e mostram, também, os diversos tipos de discriminação, deslegitimação e humilhação que existem, especificamente, para marcar ou impedir tarefas desenvolvidas por mulheres. Por exemplo, há o gaslighting, que utiliza de alegações de loucura para desvalorizar um trabalho realizado por mulher, e o bropriating que, simplesmente, descarta o trabalho por saber que foi executado por mulher (AIRES et al, 2018).

Esses dados demonstram que trabalhar o tema das mulheres com atuação profissional nas Ciências Exatas é uma necessidade para além de mercado, isto é, para o desenvolvimento de uma sociedade menos preconceituosa e mais respeitosa para o bem-estar social, o que está diretamente ligado a sentimentos que também alimentam a violência contra a mulher.

Diante do cenário apresentado, as desigualdades de gênero nas Ciências Exatas tornam-se mais relevantes. Não só para a profissão de cientista, mas para o mundo de trabalho em geral, a ausência de mão de obra qualificada afeta o desenvolvimento geral de uma sociedade. A não participação das mulheres nessas áreas colabora para a carência de inteligência e inovação no setor correspondente, contribuindo com a estagnação e declínio das empresas (ISACA, 2016). A participação das mulheres nessas áreas pode colaborar, portanto, com transformações sociais e econômicas, pois podem contribuir com seu conhecimento e, inclusive, com seus posicionamentos diferentes.

Além da necessidade econômica, mas não menos importante, a luta para diminuir a desigualdade de gênero nas áreas profissionais deve seguir em função de reduzir preconceitos e estigmas, de modo a dar o direito de participação e escolha para as mulheres, fomentar a inclusão social e a diversidade de ideias, superando escolhas pautadas no gênero biológico ou na pressão social. Se isso for feito de maneira articulada a problemas sociais como é a quantidade de mulheres em situação de vulnerabilidade, pode-se colaborar com a mitigação dos dois problemas. Por essa razão, a próxima seção descreve algumas ações do Instituto Federal de Goiás (IFG) em função dos problemas discutidos anteriormente e detalha um pouco mais a ação específica para mulheres em situação vulnerável, o curso Mulheres na Informática. 


\section{AÇÕES DE EXTENSÃO NO IFG}

O IFG, por meio de ações conhecidas por Cursos de Extensão, visa oferecer formações para demandas de seguimentos específicos da comunidade, os quais podem ser empresas, públicas ou privadas, associações, instituições filantrópicas, etc. Os cursos de extensão têm como prerrogativa atender a comunidade externa ao IFG, por meio de demandas identificadas em relação dialógica com as instituições da região, isto é, caracterizam-se como curso de extensão aquelas ações que têm suas vagas disponibilizadas para a comunidade externa e a partir das demandas dela.

O Plano de Desenvolvimento Institucional (PDI) vigente no IFG confirma o interesse dessa instituição em buscar a indissociabilidade das políticas de ensino, pesquisa e de extensão e reafirma "compromissos institucionais com políticas, programas, eventos e atividades voltadas para a educação inclusivas e para o respeito à diversidade" (IFG, 2018b). Além disso, o documento do PDI/ IFG atesta em seus objetivos o compromisso com a sociedade que rodeia seus campus, para além de seus alunos regulares em cursos superiores:

\footnotetext{
- Desenvolver atividades de extensão de acordo com os princípios e finalidades da educação profissional e tecnológica, em articulação com o mundo do trabalho e com os segmentos sociais, com ênfase na produção, desenvolvimento e difusão de conhecimentos científicos, tecnológicos, ambientais e culturais; [...]
}

- Manter constante diálogo com os arranjos produtivos, sociais e culturais locais por meio da institucionalização de projetos de ensino, de pesquisa e de extensão, com o objetivo de formar pessoas aliadas às comunidades no desenvolvimento da ciência e da tecnologia em prol da emancipação social (IFG, 2018b, p. 14).

Diante dos objetivos institucionais do IFG supramencionados, em torno de 22 cursos de extensão foram ou estão sendo ofertados, de 2015 a 2019, no câmpus Inhumas. Tais ações possuem carga horária de 41 a 160 horas de duração para públicos diversos e estão ligadas, principalmente, as áreas de Literatura, Redação, Língua Inglesa, Música, Leitura, Letramento Informacional e Informática. Todos esses cursos são oferecidos gratuitamente à população.

Os cursos ligados à área das Tecnologias da Informação e Comunicação (TIC) que vem sendo oferecidos são: Informática para gestores, Competências Digitais para Iniciação Científica, Informática Básica para estudantes de escolas públicas, Introdução à Criação de Sites e Mulheres na Informática. Vale 
destacar que, em anos anteriores, foram oferecidos também Informática Básica para Idosos e Uso pedagógico de TIC para professores, turmas que apresentam demanda também na atualidade, mas é preciso reorganizar a mão de obra no IFG para quem possam ser reofertadas.

A partir da referida necessidade de atender comunidades locais específicas, as vagas ofertadas por meio dos cursos de extensão devem ser, em $80 \%$, destinadas à população em geral que não é estudante nem servidor no IFG.

Além desse compromisso com as comunidades locais, as ações de extensão no IFG têm objetivos formativos para o seus alunos de cursos regulares. Isto quer dizer que deve haver a participação de alunos dos cursos de nível médio e de nível superior na organização e execução das ações de extensão, o que lhes possibilitará amplo enriquecimento de sua formação geral, formação para cidadania e momentos de colocar em prática diversos conhecimento técnicos, específicos da área do curso que estudam. De 2015 a 2019, pelo menos de 12 bolsistas, originários dos cursos técnicos em Informática ou do Bacharelado em Sistemas de Informação foram protagonistas nos cursos citados, tendo ampla oportunidade de atuar como monitor e instrutor, além de aprender conhecimentos ligados às questões sociais que envolvem os grupos e de desenvolver outras habilidades técnicas e emocionais como liderança, trabalho coletivo e colaborativo, escrita de relatório técnico e de artigos, etc.

Do conjunto de cursos de extensão mencionados anteriormente, será detalhada, em seguida, a ação voltada para mulheres em situação vulnerável com a iniciação na Informática.

\section{O CURSO DE EXTENSÃO MULHERES NA INFORMÁTICA}

Considerando o contexto de vulnerabilidade social feminina e a alta demanda por profissionais da Informática, algumas ações de extensão no IFG foram propostas, estritamente, para o público feminino. Nesse conjunto, uma dessas ações foi organizada a partir de demanda identificada junto à prefeitura de Inhumas, por meio da Secretaria de Promoção Social: o curso Mulheres na Informática, em que o público alvo foi voltado para mulheres em situação de vulnerabilidade social comprovada por meio do Cadastro Único de mulheres em tal situação ou de análise da Promoção Social referida acima.

No que diz respeito aos conhecimentos ligados às Tecnologias Digitais da Informação e Comunicação (TDIC), sabe-se que são demandados por diversas profissões (LAUDON; LAUDON, 2006), ou seja, ainda que as mulheres participantes 
do projeto não optem por aprofundar em tal área profissional, elas terão aprendido importantes conhecimentos e ferramentas que lhes ajudarão em qualquer exercício profissional.

A partir da delimitação da Informática como eixo principal da formação, o curso foi pensado dentro da concepção de articulação entre formação técnica e humana, visando à formação integral das estudantes, o que é consonante com as diretrizes formativas para os institutos federais: Formação "com estreito compromisso com o desenvolvimento integral do cidadão trabalhador" (BRASIL, 2010, p. 14). Nesse sentido, o projeto do curso de extensão intitulado "Mulheres na Informática" foi organizado em 160 horas, distribuídas em dez meses, com conteúdos de informática básica criativa, empreendedorismo, criação de sites e empoderamento feminino.

A informática básica criativa compreende os conteúdos técnicos do pacote de escritório com exercícios contextualizados de maneira interdisciplinar com temas que evidenciam relações com a sociedade: a) Descarte de lixo eletrônico; b) Crimes digitais (cyberbullying, compartilhamentos ilegais, etc.); c) Doenças a partir de uso excessivo de TDIC (Nomofobia, náusea digital, vícios, etc.). Os conteúdos de empreendedorismo, criação de sites e empoderamento feminino trabalham os interesses profissionais de cada estudante, as incentiva a pensar sua reinserção profissional e também se apóia em leituras dos temas que refletem, criticamente, as relações entre TDIC e sociedade.

A concepção de formação que norteia a metodologia de ensino do curso em questão é a Teoria Histórico-Cultural (LURIA, 2008; VYGOTSKY, 1931; VYGOTSKY, 1991; VYGOTSKY; LURIA, 2007), a qual explica que a inteligência humana não é nata, sendo isso debatido com as mulheres participantes visando dar-lhes motivação e força para a própria transformação social. De acordo com Vygotsky (1931, p. 21), “[...] o desenvolvimento cultural se sobrepõe aos processos de crescimento, amadurecimento e desenvolvimento orgânico da criança, formando com ele um todo. Constituem, em realidade, um processo único de formação biológico-social". Isto quer dizer que a qualidade da educação faz diferença no desenvolvimento geral do ser humano, pois, pode ou não desenvolver uma ou outra área. Adiante, o autor explica que "os processos naturais são uma função determinada pelos procedimentos artificiais. Os processos naturais se aplicam onde não existem procedimentos artificiais e se empregam para facilitar a utilização destes últimos" (SOFTEX, 2013b, p. 183).

Vygotsky (1931; 1991) e Luria (2008; apud AKHUTINA, 2013) explicam que o desenvolvimento intelectual não nasce pronto e, também, não para jamais: 
A instrução formal, que altera radicalmente a natureza da atividade cognitiva, facilita enormemente a transição das operações práticas para as operações teóricas. Assim que as pessoas adquirem instrução formal, fazem uso cada vez maior da categorização para exprimir ideias que refletem objetivamente a realidade. A significância da escolaridade está não somente na aquisição de novos conhecimentos, mas também na criação de novos motivos e modos formais de pensamento verbal, discursivo e lógico divorciado da experiência prática imediata. (LURIA, 2008, p. 133; 178).

A instrução formal refere-se aos processos de escolarização. Pela apropriação do conhecimento sistematizado, em atividade, é que o homem desenvolve as capacidades intelectuais e motoras. Isto quer dizer que "a potencialização das ações intelectuais se dá pelo processo de apropriação-interiorização dos mediadores culturais e dos seus modos de ação internos que, quando apropriados pelo sujeito em atividade, se convertem em meios internos de mediação do sujeito com o mundo" (COSTA, 2015, p. 96). As pesquisas da psicologia social vygotskyana comprovam, portanto, que a inteligência matemática, que tanto amedronta, não é nata, mas sim desenvolvida conforme a participação cultural. Desse modo, a formação técnica e humanística são contempladas de maneira crítica e criativa.

Os encontros do curso que trabalham o empoderamento feminino integram ações como palestras conscientizando as mulheres participantes de que a inteligência delas pode ser desenvolvida ao longo da vida, conforme buscam esse tipo de ação de estudo e formação. Tais encontros incluem também dinâmicas com a assistente social do câmpus, visando ajudar o público feminino a repensar sua situação, seu poder de decisão.

O curso em questão, Mulheres na Informática, teve 50 vagas disponibilizadas, mas apenas 28 foram preenchidas. Está no seu quarto mês de execução e conta com 20 estudantes. $\mathrm{O}$ acompanhamento durante o curso mostra que embora haja muitas mulheres com necessidades de reinserção no mercado, ainda é preciso desenvolver estratégias para seu interesse e manutenção num curso na área de Informática. Os problemas mais diagnosticados são em relação à situação vulnerável como, por exemplo, mães solteiras, mães com filhos pequenos e sem onde deixar a criança. Mais da metade das inscritas, 55\%, possui entre 22 e 39 anos e tinham completado, no máximo, até o Ensino Médio.

Todas as 28 inscritas afirmaram ter pouco ou nenhum conhecimento em Informática, embora 26 delas tenham afirmado que utilizam a Internet todos os dias via celular. Além disso, 76\% declarou ter interesse nas áreas de Humanas ou Biológicas.

Destaca-se, ainda, que os cursos de extensão proporcionam impactos significantes na formação dos estudantes do IFG que neles participam como bolsistas. $\mathrm{O}$ 
IFG estimula o protagonismo dos estudantes de cursos de bacharelado, licenciaturas e cursos técnicos apoiando as ações de extensão, pois nessas ações, eles têm a oportunidade de consolidar conhecimentos técnico-científicos aprendidos no seu curso de origem, bem como ter contato com questões sociais locais e globais que se manifestam em sua região. Assim, a Extensão é compreendida como princípio educativo que enriquece a formação dos universitários, ao mesmo tempo que amplia as formas atendimento à sociedade local e reafirma os propósitos da instituição como aberta às necessidades do seu entorno. A ação de extensão aqui descrita conta com duas bolsistas do curso superior em Sistemas de Informação.

Nos últimos dois anos, foi possível observar, em torno de 15\%, que alunos de curso de extensão procuraram os cursos superiores ou técnicos de nível médio para continuar sua formação na Instituição. Isso colabora com a área do curso e mostra que serviu de divulgação das outras formações que a instituição oferece. Em torno de 10\%, escolheu continuar no curso, superior ou técnico, da mesma área do curso de extensão que o levou à Instituição.

\section{CONSIDERAÇÕES FINAIS}

Consideradas as relações entre violência, desigualdade de gênero, vulnerabilidade social (IPEA, 2018; ROCHA et al, 2015; 2017) e a importância da Informática (ISACA, 2016; LAUDON; LAUDON, 2006) para inclusão profissional em qualquer área, bem como o déficit de mão de obra na área de TI no mundo, a ação de extensão apresentada durante este texto colabora a formação de jovens mulheres em situação de pobreza e com a articulação com o mundo do trabalho. Quanto à formação ser específica a um grupo de mulheres em situação vulnerável, no caso do Estado de Goiás, é uma ação de relevância, tendo em vista ser um dos estados brasileiros que mais apresenta violência contra mulheres. Nesse sentido, é evidente a importância desse tipo de ação para o desenvolvimento geral das estudantes e transformação local. Além disso, o foco específico dessa ação contribui com a desconstrução dos preconceitos e mitos que consolidaram, ao longo da história humana, a respeito da inferiorização da inteligência feminina.

Outro importante benefício que merece destaque é a divulgação das ações institucionais por meio da ação de extensão, o que traz credibilidade junto à comunidade e abre espaço para futuros projetos em parceria com outras instituições.

Os dados coletados a respeito da situação doméstica de cada inscrita comprovam que tal situação é, para maioria delas, fator que colabora para a desistência do curso, pois têm dificuldades para ter ajudante para ficar com filhos pequenos. Isso 
mostra que, mais do que oferecer o curso gratuitamente, é preciso desenvolver estratégias para manter tais mulheres na formação até seu final.

No que toca à área de Informática, mesmo sendo esclarecidas sobre a área nas primeiras aulas, bem como sobre a amplitude do mercado de trabalho e das vastas possibilidades de trabalho, a maioria delas disse ter mais interesse profissional nas Ciências Humanas ou nas Biológicas, o que demonstra que os movimentos em função das mulheres nas Exatas são importantes e precisam continuar acontecendo.

Por fim, a análise dos dados apresentados comprova a necessidade de não se abandonar, no Brasil, os investimentos em políticas de assistência social e educação pública, esta em todos os níveis, pois há uma grande parcela da população que necessita desse tipo de auxílio, inclusive para requalificação e reinserção no mercado de trabalho. Ademais, os investimentos em educação são condição sine qua non para recolocação social, consequentemente, influenciando os índices de desenvolvimento e violência no país.

\section{REFERÊNCIAS BIBLIOGRÁFICAS}

AKHUTINA, T. A. R. Luria: uma trajetória de vida. In: LONGAREZI, A. M. e PUENTES, R. V. (Orgs.) Ensino desenvolvimental: vida, pensamento e obra dos principais representantes russos. Uberlândia: EDUFU. 2013.

AIRES, J.; MATTOS, G.; OLIVEIRA, C.; BRITTO, A.; ARAGÃO, A. F.; ALVES, S.; COELHO, T.; MOREIRA, G. Barreiras que Impedem a Opção das Meninas pelas Ciências Exatas e Computação: Percepção de Alunas do Ensino Médio. In: Anais do XXXVIII Congresso da Sociedade Brasileira de Computação (SBC) / $1^{\circ}$ WIT - Women in Information Technology. UFRN - Natal, de 22 a 26 de julho de 2018. Disponível em: http://natal.uern. br/eventos/csbc2018/?page_id=370. Acesso em: 27 set. 2018.

BARRETO, A. A mulher no ensino superior: distribuição e representatividade. Cadernos do GEA, n. 6, jul./dez. 2014. Disponível em: http://flacso.org. br/files/2016/04/caderno_gea_n6_digitalfinal.pdf. Acesso em: 27 set. 2018.

BOLZANI, V. da S. Mulheres na ciência: por que ainda somos tão poucas?. Cienc. Cult., São Paulo, v. 69, n. 4, p. 56-59, Oct. 2017. Disponível em: http:// dx.doi.org/10.21800/2317-66602017000400017. Acesso em: 27 set. 2018. 
BRASIL. Um Novo Modelo de Educação Profissional e Tecnológica: Concepções e Diretrizes. 2010. Disponível em: http://portal.mec.gov.br/index. php?gid=6691\&option=com_docman\&task=doc_download.

Acesso em: 19 fev. 2019.

MEC. Base Nacional Curricular Comum (BNCC). Homologada em 20 de dezembro de 2017. Disponível em: http://basenacionalcomum.mec.gov. br/a-base/. Acesso em: 08 mar. 2018.

CHASSOT, A. A ciência é masculina? 5. ed. São Leopoldo: Editora Unisinos, 2011a. 134 p.

CHASSOT, A. A ciência é masculina? É, sim senhora!... Programa de Pós-Graduação Unisinos. 2011b. Disponível em: http://www.cimm.ucr.ac.cr/ ciaem/memorias/xii_ciaem/124_ci encia_masculina.pdf. Acesso em: 28 nov. 2013.

COSTA, R. L. Educação Profissional Técnica de nível médio a distância: estudo da mediação docente no modelo da Rede e-Tec Brasil na rede federal. Goiânia, 2015. Tese (doutorado) - Pontifícia Universidade Católica de Goiás, Programa de Pós-Graduação Stricto Sensu em Educação.

CUNHA, M. B. da; PERES, O. M. R.; GIORDAN, M.; BERTOLDO, R. R.; MARQUES, G. de Q.; DUNCKE, A. C. As mulheres na ciência: o interesse das estudantes brasileiras pela carreira científica. Educ. Quím., 25 (4), 407-417, 2014.

IAB. Interactive Advertising Bureau Brasil. A liderança alfa e as empresas de TI no universo feminino. 2015. Disponível em: http://iabbrasil.com.br/a-lideranca-alfa-e-as-empresas-de-ti-no-universo-feminino/. Acesso em: 24 maio 2017.

IBGE. Instituto Brasileiro de Geografia e Estatística. Estatísticas do cadastro central de empresas. Rio de Janeiro. 2017. 
IFG. Plano de Desenvolvimento Institucional - PDI. 2018b. http://www. ifg.edu.br/documentos/62-ifg/a-instituicao/11546-plano-de-desenvolvimento-institucional-2019-2023. Acesso em: 19 fev. 2019.

IPEA. Atlas da Violência no Brasil. Fórum Brasileiro de Segurança no Brasil. 2018.

ISACA. Information Systems Audit and Control Association. The future tech workforce: breaking gender barriers. 2016. Disponível em: http://www.isaca.org/info/2017-women-in-technology-survey/index.html. Acesso em: 25 maio 2017.

LAUDON, K. C.; LAUDON, J. P. Sistemas de informação gerenciais: administrando a empresa digital. 5. ed. São Paulo: Pearson Prentice Hall, 2006.

LURIA, A. R. Desenvolvimento Cognitivo: seus fundamentos culturais e sociais. Tradução: Fernando Limongeli Gurgueira. 5. ed. São Paulo: Editora Ícone, 2008.

MACEDO, M. M. G.; MATTOS, A. B.; VASCONCELOS, M.; MARTINAZZO, A.; LOPES, R. Identificando Influências na Escolha de uma Graduação em Exatas: um Estudo Qualitativo e Comparativo de Gênero. In: Anais do XXXVIII Congresso da Sociedade Brasileira de Computação (SBC) / $12^{\circ}$ WIT - Women in Information Technology. UFRN - Natal, de 22 a 26 de julho de 2018. Disponível em: http://natal.uern.br/eventos/csbc2018/?page_ $\mathrm{id}=370$. Acesso em: 27 set. 2018.

MAQUINÉ, C. C. Contribuição das mulheres nas ciências exatas: Levantamento histórico. Trabalho de conclusão de curso. Universidade Federal de São João Del Rey, Minas Gerais. Departamento de Licenciatura em Matemática. 2017.

ROCHA, Betty Nogueira; CURY, Rodrigo Luis Comini; MARGUTI, Bárbara Oliveira; COSTA, Marco Aurélio. A nova plataforma da vulnerabilidade social: Primeiros resultados do índice de vulnerabilidade social para a série histórica da Pnad (2011-2015) e desagregações por sexto, cor e situação de domicílio. Atlas da Vulnerabilidade Social. 2017. Disponível em: http://www. 
ipea.gov.br/portal/images/stories/PDFs/relatoriopesquisa/170823_lancamento_ivs_metodologia_e_primeiros_resultados.pdf. Acesso em: 02 mar. 2019.

ROCHA, Betty Nogueira; CURY, Rodrigo Luis Comini; MARGUTI, Bárbara Oliveira; COSTA, Marco Aurélio. A Dimensão de Gênero no Índice de Vulnerabilidade Social (IVS): Alguns Apontamentos Teóricos e Analíticos. 2015. Disponível em: http://repositorio.ipea.gov.br/bitstream/11058/7947/1/ BRU_n16_Dimens\%C3\%A3o.pdf. Acesso em: 02 mar. 2019.

SANTOS, A. C.; CANEVER, C. F.; FROTTA, P. R. de O. A influência do gênero na escolha profissional de pré-vestibulandos: estudo de caso na cidade de Criciúma/SC. Revista Travessias, V. 5, n. 2, 2011. Disponível em: http://e-revista.unioeste.br/index.php/travessias/article/view/5741/4325. Acesso em: 20 set. 2018.

SOFTEX. Cadernos Temáticos do Observatório: Mercado de Trabalho e Formação de Obra em TI - SOFTEX, 2013a. Arquivo eletrônico disponível em: https://www.softex.br/inteligencia/\#cadernostematicos. Acesso em: 20 set. 2018 .

SOFTEX. Cadernos Temáticos do Observatório: Economia da Informação e Internet - SOFTEX, 2013b. Arquivo eletrônico disponível em: https://www. softex.br/inteligencia/\#cadernostematicos. Acesso em: 20 set. 2018.

VYGOTSKY, L.S. PenSamento e Linguagem. São Paulo: Martins Fontes, 1998.

VYGOTSKY, L. S. Historia del Desarrollo de las Funciones Psíquicas Superiores. Obras Escogidas Tomo III. Comisión editorial para la edición en lengua rusa. Academia de Ciencias Pedagógicas de la URSS. 1931.

VYGOTSKY. L.; LURIA, A. El instrumento y el signo en el desarrollo del niño. San Sebastián de los Reyes Madrid: Fundación Infancia y aprendizaje, 2007. 